\title{
Inverse Airfoil Design Method for Low-Speed Straight-Bladed Darrieus-Type VAWT Applications
}

\author{
F. Saeed ${ }^{*}$ \\ King Fahd University of Petroleum \& Minerals, Mail Box 1637, Dhahran 31261, Saudi Arabia \\ I. Paraschivoiu, ${ }^{\dagger}$ O. Trifu $^{\ddagger}$ \\ Ecole Polytechnique de Montreal, Montreal, H3C 3A7, Canada \\ M. Hess, ${ }^{\S}$ and C. Gabrys ${ }^{* *}$ \\ Mariah Power Inc., 748 South Meadows Parkway A-9, \#329, Reno, Nevada 89521, USA
}

Key words: VAWT, straight-bladed VAWT, Darrieus-type VAWT, airfoil design, multipoint airfoil design, inverse airfoil design, low Reynolds number airfoil design, low speed airfoil design.

\section{Abstract}

The paper demonstrates the application of inverse airfoil design method to improve performance of a low-speed straight-bladed Darrieus-type VAWT. The study shows that an appropriate tailoring of the airfoil surface using the inverse airfoil design technique can help improve performance by eliminating undesirable flow field characteristics at very low $\mathrm{Re}$, such as early transition due to presence of separation bubbles. The increase aerodynamic efficiency then translates into an improved aerodynamic performance of VAWTs specifically at very low chord Reynolds numbers. The study employs an interactive inverse airfoil design method (PROFOIL) that allows specification of velocity and boundary-layer characteristics over different segments of the airfoil subject to constraints on the geometry (closure) and the flow field (far field boundary). Additional constraints to satisfy some desirable features, such as pitching moment coefficient, thickness, camber, etc., along with a merit of performance of the VAWT, such as the required power output for a given tip-speed ratio, are specified as part of the inverse problem. Performance analyses of the airfoil and the VAWT are carried out with the aid of state-of-the-art analyses codes, XFOIL and CARDAAV, respectively. XFOIL is a panel method with a coupled boundarylayer scheme and is used to obtain the aerodynamic characteristics of resulting airfoil shapes. The final airfoil geometry is obtained through a multi-dimensional Newton iteration. A design example is presented to demonstrate the merits of the technique in improving performance of small VAWTs at low speeds. The main findings of the study suggests that the strength of the method lies in the inverse design methodology whereas its weaknesses is in reliably predicting aerodynamic characteristics of airfoils at low Reynolds numbers and high angles of attack. This weakness can, however, be overcome by assessing relative performance of the VAWT with the assumption that the changes in airfoil characteristics be kept small. The results indicate that a $10-15 \%$ increase in the relative performance of the VAWT can be achieved with this method.

\footnotetext{
*Assistant Professor, Aerospace Engineering Department.

Corresponding author. Email: faroogs@kfupm.edu.sa

${ }^{\dagger}$ Professor, Mechanical Engineering Department.

${ }^{\ddagger}$ Research Associate, Mechanical Engineering Department.

${ }^{\S}$ Chief Executive Officer (CEO).

Chief Technical Officer (CTO).
} 


\section{Background}

Ever since the rediscovery of the Darrieus rotor concept by Peter South ${ }^{1}$ and coworkers at the Canadian Research Council in 1968, extensive research effort has been devoted towards the maturity of VAWT performance prediction models, the question of the optimum performance remains unanswered to this day. There remain several unanswered concerns that need to be carefully examined and systematically addressed in order to truly realize the potential of the Darrieus-type VAWT (DVAWT).

The first concern is in regards to the aerodynamic efficiency of a D-VAWT. It is an established fact that the aerodynamic efficiency of a D-VAWT is greatly influenced by the choice of airfoil geometry as reflected in several studies, ${ }^{2-9}$ analytical as well as experimental. To be able to predict the performance reliably, accurate airfoil aerodynamic characteristics data, in terms of airfoil section lift, drag and moment coefficients ( $c_{l}, c_{d}$, and $c_{m}$ respectively), is needed for a range of angles of attack ($180<\alpha<180 \mathrm{deg})$ as well as a chord Reynolds number $\left(R e_{c}\right)$ range from as low as 50,000 to as high as 3 million depending on the size of the VAWT. The majority of airfoil section force and moment coefficient data available in literature to-date is based on airfoils that were designed for a host of aircraft, rotorcraft and propeller applications $^{10,11}$ and is limited to an angle of attack range of just past stall since the utility of these airfoils is limited to an angle of attack range between zero-lift angle and the stall. Seldom are these airfoils required to operate in stall or post-stall conditions.

The blades on a VAWT, on the other hand, operate on a wide range of angles of attack. Moreover, because of the cyclic nature of VAWT, the blade airfoil undergoes through both stall, positive and negative (flow separating on the upper and lower surfaces, respectively), and post-stall regimes. Since blade performance in the stall region determines the actual rating of the turbine, the nature of stall is of quite significance for optimum design. Availability of experimental test section data at low chord Reynolds number specifically around stall and in the post-stall regime is very

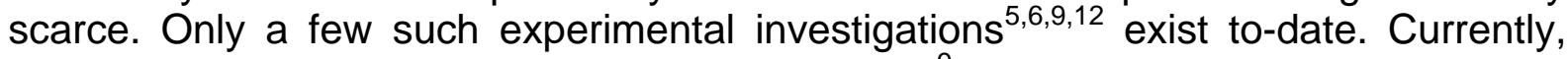
experimental aerodynamic characteristics data $^{9}$ is available for only seven symmetrical (NACA 00xx) airfoil sections. The data for other airfoils (NACA 6-series, ${ }^{8}$ Natural Laminar Flow (NLF) airfoils, ${ }^{6}$ etc.) has been obtained through a "ThreeSource Section Data" technique. ${ }^{6}$ A limitation of the "Three-Source Section Data" technique is its inability to model the stall and its hysteresis behavior accurately, in general, and at low chord Reynolds numbers, in particular. This limitation remains to this day and is mainly due to a lack of understanding and ability to numerically predict the post-stall behavior. Experimental investigations ${ }^{13-17}$ show that stall characteristics are strongly dependent on the airfoil geometry as well as chord Reynolds number. Furthermore, operation of airfoil at low chord Reynolds number has the tendency of aggravating the stall and its hysteresis characteristics. Since an accurate prediction of stall and post-stall characteristics is essential for a reliable prediction of the aerodynamic efficiency of a VAWT, the capability to accurately predict airfoil aerodynamic characteristics throughout the entire 360-deg angle of attack range as well as at low chord Reynolds number must be inherent in the performance analysis toolbox for VAWT. 
The second concern arises from the fact that airfoils for small-scale VAWTs operate at low Reynolds number. In the past, airfoil aerodynamic characteristics data has been extrapolated from known higher values of chord Reynolds number to obtain values for very low chord Reynolds number. It is now a known fact that at low Reynolds number $\left(50,000<\mathrm{Re}_{c}<500,000\right)$ airfoils suffer from laminar separation bubbles $^{11,18}$ which lead to aerodynamic performance degradation. At low Re, the laminar boundary layer cannot withstand strong/prolonged adverse pressure gradients $(d p / d x>0, d U / d x<0)$ and has a strong tendency to separate from the airfoil's surface. In the separated zone the flow instability increases and leads to a transition to turbulent flow. Under certain conditions the turbulent boundary layer reattaches to the surface closing a so called "laminar separation bubble". These separation bubbles appear as a plateau followed by transition and a steep increase in pressure in the surface pressure distribution plots and tend to move forward towards the airfoil leading edge as the angle of attack is increased. The presence of separation bubbles results in an additional "bubble" drag and thus a decrease in the airfoil's aerodynamic efficiency. This effect is further aggravated by roughness effects resulting from airborne particles or insect strikes.

One of the techniques for reducing bubble drag is through the use of boundary-layer trips to either completely eliminate or reduce the intensity of the laminar bubble. A limitation of using trips is that a trip configuration that is beneficial for one angle of attack and $\mathrm{Re}$ condition might not be beneficial for another operating condition. A second technique for reducing bubble drag is through the use of a transition ramp. ${ }^{11,23}$ A transition ramp refers to the shape of the pressure coefficient curve that has an extended region of adverse pressure gradient to destabilize the laminar boundary layer and gradually promote transition without the occurrence of large transitional bubbles. The length, slope and arch (convex vs. concave) of the transition ramp $^{23}$ can be systematically altered to tailor the airfoil's performance for a range of operating conditions. Recently interest ${ }^{18}$ in a variety of low Reynolds number applications has focused attention on the use of transition ramps to design efficient airfoil sections at chord Reynolds numbers from about 50,000 to about 1,000,000. These applications include low-speed NLF airfoils for general aviation, ${ }^{19-21}$ remotely piloted vehicles (RPVs) at high altitudes, ${ }^{22}$ sailplanes, ${ }^{13-16}$ ultra- light mancarrying/man powered aircraft, ${ }^{23}$ propellers and wind turbines. ${ }^{17}$ This effort has resulted in improved rapid, robust, interactive airfoil design and analysis techniques ${ }^{24-}$ ${ }^{29}$ for low Reynolds number airfoil sections. In light of these new developments, it becomes imperative that these new improved design and evaluation techniques ${ }^{24-29}$ for low Reynolds number flows be employed in analyzing the aerodynamic characteristics of existing airfoils and also in the design of new airfoils for VAWT applications.

The third concern stems from the fact that the design of the optimum VAWT has never been attempted to-date. In the absence of a fast, robust and reliable airfoil aerodynamic characteristics analysis method, the traditional approach for selecting an optimum VAWT has been based on a comparison of the annual cost of energy production of the VAWT employing different airfoil sections or a combination thereof, the aerodynamic characteristics of which were determined experimentally. Scarcity of airfoil aerodynamic characteristics data as well as design constraints, e.g. airfoil thickness for structural integrity and stiffness etc., further limits the choice of candidate airfoils to a few. Design and use of low-speed symmetric NLF airfoils ${ }^{2,3}$ 
(SNLA 00xx/yy, where $x x=\% t / c$, yy $=\% x / c$ : extent of laminar region), an idea taken from the low-speed NLF airfoil design for general aviation aircraft, has proved to be a disappointment for large-scale VAWTs. However, there is speculation that these airfoils may result in superior performance of small-scale VAWTs. Similarly, use of cambered airfoils for increased performance have also been suggested by several investigators. $^{12,30}$ In order to verify these findings, a design method for an optimum VAWT must be capable of reliably predicting the blade airfoil aerodynamic characteristics at all angles of attack and chord Reynolds numbers. The design can then be accomplished by a direct technique, also known as the design-by-analysis approach, or by an inverse technique. ${ }^{31}$ In the direct design technique, a procedure of repeatedly analyzing candidate geometries that successively approaches the desired objectives is employed. On the other hand, in the inverse design technique, the desired VAWT performance characteristics along with some initial blade and airfoil aerodynamic characteristics subject to some constraints (e.g., maximum airfoil thickness, etc.) are specified from which the corresponding VAWT blade geometry is determined through successive iterations on some other airfoil and blade geometric or aerodynamic characteristics.

As a first step towards addressing these concerns, development of an interactive design and analysis toolbox becomes imperative. Such a toolbox must have the following minimum capabilities:

a. Multipoint inverse airfoil design (PROFOIL ${ }^{28,29,33-35}$ )

b. State-of-the-art airfoil aerodynamic analysis (XFOIL ${ }^{24}$ or $\mathrm{MSES}^{27}$ )

c. VAWT performance analysis (CARDAAV ${ }^{2}$ )

With such a toolbox at hand, parametric studies can be performed to determine the relationship between the various design variables. The toolbox can also help in assessing various trade-offs in the design. For instance, since power output is directly related to the tangential force which in turn is related to airfoil section aerodynamic characteristics along the azimuthal direction, the tool box can address questions such as: what airfoil characteristics (such as range of $c_{l}, c_{/ \max }$, transition, stall characteristics, etc.) can lead to an increase in the tangential force along the azimuth?

In the sections that follow, an inverse design methodology for the design of airfoils for an improved performance of VAWT is presented. A typical low-speed straight-bladed Darrieus-type VAWT example is used to demonstrate the design strategy and the resulting increase in performance. The strengths and weaknesses of the method are discussed in light of the example study case. The paper ends with conclusions and recommendations for future work.

\section{The Inverse Airfoil Design Methodology}

An inverse airfoil design technique is one in which the airfoil geometry is obtained from a specification of desired velocity distribution(s) subject to certain constraints. The method is based on conformal mapping of flow around a circle (known) to that around the airfoil (desired) through conformal transformation. The strength of the method lies in its two main features: (1) the derivative of the transformation rather than the transformation is of importance and is easily related to the desired velocity distribution, and (2) multipoint capability. The latter is achieved by dividing the circle into a number of arc segments that relate to equal number of segments on the airfoil 
where the desired velocity distribution(s) are specified. Typically, good performance is required over a range of angles of attack. For example, as shown in Fig. 1, high-lift (high angle of attack) performance may be required as well as low-lift (low angle of attack). Thus, for instance, upper surface velocity distribution can be prescribed for a high angle of attack while simultaneously lower surface velocity distribution can be prescribed for a low angle of attack. Since the velocity distribution corresponds to the lift coefficient which in turn depends on the angle of attack, the velocity distribution along different airfoil segments can be related to different angle of attack conditions, i.e., $\alpha^{\star}$ (alpha-star) or $C_{l}^{*}$. A good approximation is given by $C_{l}^{\star}=2 \pi(1+0.78 t / c) \sin \alpha^{\star}$, where $t / c$ is the airfoil thickness-to-chord ratio and $\alpha^{\star}$ corresponds to the zero-lift line. The resulting airfoil will, therefore, exhibit the design characteristics (velocity distribution and $C_{l}^{*}$ ) when operated at the corresponding $\alpha^{\star}$.

In order to achieve practical airfoils, the derivative of transformation must be continuous at the junction of two segments (continuity constraints), and that the airfoil trialing edge be closed (closure constraint), in addition to the condition that the far field flow remain unaltered, the satisfaction of these constraint leads to a system of $(\mathrm{N}+3)$ equations where $\mathrm{N}$ is the number of segments. As mentioned earlier, the specification of the velocity distributions is not completely arbitrary. It must contain an equal number of unknowns $(\mathrm{N}+3)$ to obtain a solution of the problem. Typically these unknowns are the velocity levels on (N-1) segments, and the remaining 4 variables define the form of the recovery and closure functions for flow at the trailing edge along the upper and lower surfaces. Additional constraints (dependent variables) such as pitching moment, maximum thickness, camber, etc., can also be imposed and satisfied through an iterative procedure by varying some independent variables in the design, such as the variables defining closure and recovery functions. Simultaneous solution of the constraints requires a multi-dimensional Newton iteration scheme and is accomplished within 10-15 iterations. Details of the mathematical formulation and various applications of the method are described in greater detail in the works of Eppler, Selig, and Saeed. In the present study, the PROFOIL code is used as an interactive airfoil design tool.

To evaluate performance of a VAWT, the computer code CARDAAV ${ }^{2}$ is used. The code is based on the Double-Multiple Stream Tube (DMSV) model with variable upwind- and downwind-induced velocities in each streamtube. The program allows multiple options for geometrical configuration, operational conditions and the control of the numerical process. These features make CARDAAV a reliable simulation tool, meeting the needs of VAWT designers. It computes the aerodynamic forces and the power output for VAWTs of arbitrary geometry at given operational conditions. It also has the capability to take into account the effect of finite blade span or the blade-tip effects, the occurrence of the dynamic stall, and several "secondary effects", such as the effect of the wake of the rotating central column, and the drag of struts and spoilers. Detailed descriptions of the DMSV model and of the CARDAAV code capabilities are given in Ref. 2.

Since the performance of the VAWT depends on the aerodynamic characteristics of its blade sections, a reliable and accurate prediction of airfoil aerodynamic and boundary layer characteristics in needed. In the current study, the XFOIL ${ }^{24}$ code is utilized for this purpose. XFOIL is a panel method with a coupled boundary-layer scheme. It has excellent airfoil design (direct and indirect) and analysis capabilities 
and is used extensively for such purpose. In the current study it is used to obtain the aerodynamic characteristics of airfoils.

As a first step, the PROFOIL, CARDAAV and XFOIL codes were coupled to form an interactive design and analysis toolbox for the current study. A self-explanatory diagram illustrating the working of the newly created toolbox and the strategy used in applying the inverse design technique for an improved airfoil design for VAWT applications is shown in Fig.1. The figure of merit selected for the design is an improvement of $10-15 \%$ in power output for a tip-speed ratio of 1.6 (typical of small VAWTs). The strategy used is evaluation of VAWT's power output at successive design iterations until the above criteria or figure of merit is met. Each iteration cycle as depicted in Fig. 1 is performed interactively. Next, a design example is presented to demonstrate the use of inverse design technique in improving performance of small VAWTs at low speeds.

\section{Design Example}

The VAWT geometry along with the operational conditions used in this study are: 3 straight-bladed rotor with constant NACA 0018 section having chord of $0.125 \mathrm{~m}$, length $6 \mathrm{~m}$, and 6-m rotor diameter. The mid-span height of rotor is at $3.048 \mathrm{~m}$ above ground. A wind speed of $12 \mathrm{~m} / \mathrm{s}$ is fixed with a shear component of $\alpha_{w}=0.16$. A constant rotational speed of $30 \mathrm{rad} / \mathrm{s}$ has also been fixed. The effects of struts, tower wake and finite span blade have all been neglected. The dynamic stall is modeled with the Berg's ${ }^{36}$ version of the Gormont model, with $A M=1000$ suited for small VAWTs. For these conditions, the azimuthal variation of the local angle of attack and the Reynolds number on a blade element is: $45000<\operatorname{Re}<250000$ and $-37.70<\alpha<$ 41.59 deg. The airfoil aerodynamic characteristics were obtained from XFOIL for $75000<\operatorname{Re}<230000$ and $-20<\alpha<20$ deg. Figure 2 shows the computed drag polars, lift and transition curves for the NACA 0018 (original) and NACA 0018-M (modified) airfoils at $\mathrm{Re}=200000$ as compared to the experimental results for $\mathrm{Re}=$ 200000 and 300000. Although aerodynamic coefficients are independent of airfoil geometry beyond $|\alpha|>27-30 \mathrm{deg}$, the limitation of XFOIL to accurately predict these coefficients for low Re high $\alpha$ values, as evident from Fig. 2, results in uncertainty in accurately predicting the power output of the VAWT. This uncertainty can, however, be overcome by comparing the relative increase in power output as predicted by the analysis toolbox for both the actual NACA 0018 airfoil and the newly designed airfoil, referred to by the designations NACA 0018 and NACA 0018-M, respectively.

As mentioned earlier, the length, slope and shape/arch (convex vs. concave) of the transition ramp ${ }^{23}$ can be systematically altered to tailor the airfoil's performance for a range of operating conditions. This is specifically the strategy employed in the inverse airfoil design technique. It is accomplished by a systematic choice of the design angles of attack distribution or $\alpha^{*}$-distribution (as shown in Fig. 1) along the upper surface segments. Since it is desired that the airfoil be symmetric, a similar $\alpha^{*}$ distribution with same magnitude but opposite sense is specified along the lower surface segments. Since the $\alpha^{*}$-distribution will translate into the corresponding velocity distribution, a uniform increase in $\alpha^{*}$-values is specified from trailing to the leading edge with uniform steps size to avoid corners in the velocity distribution. Additional constraints such as maximum thickness-to-chord ratio $18 \%$ and zeropitching moment are also imposed so as to obtain an airfoil similar to NACA 0018 as 
much as possible. The pitching moment constraint is satisfied by iterating on the first segment velocity level whereas the thickness-to-chord requirement is satisfied through a step increase/decrease in the specified $\alpha^{*}$-values. In addition, values of parameters defining the trailing edge thickness ratio and velocity recovery functions are specified as well as part of the input.

Starting from these initial set of inputs, inverse design method was employed in an interactive manner to guide the design of successive airfoils towards achieving the objective. Figure 3(a) shows the different intermediate airfoil designs whereas; Fig. 3(b) shows the final design (NACA 0018-M) as compared to the original NACA 0018 airfoil. Figure 4 shows a comparison of the pressure coefficient distribution for the two airfoils with a longer transition ramp for the final airfoil. It is noted here that since the design objective of $15 \%$ more power output was met by the design, no further design iterations were attempted. A look at the transition curves in Fig. 2 for the two airfoils shows that the transition occurs later for the final design for all angles of attack, yet it has a slightly higher drag at low angles of attack. An explanation for this may lie in the fact that the pressure recovery is still quite steep for the final design leading to greater pressure drag. The increase power output of the VAWT for the final airfoil design is evident from the lift curve slopes of the two airfoils in Fig. 2. Moreover the final airfoil design also exhibits much less drag at $\alpha>15$ deg. Table 1 shows a comparison of power output $P$, power coefficient $C_{P}$ and the torque coefficients $C_{Q}$. Again it is mentioned here that the $15 \%$ increase in power output should be viewed in terms of relative increase in power output as predicted by the analysis toolbox for both the actual NACA 0018 airfoil and the final airfoil design. The study shows that there is still a lot of room for improvement in the final design as well as flow analysis capabilities for low Re flows.

\section{Conclusions}

In this study, the use of inverse design methodology for the design of airfoils for lowspeed straight-bladed Darrieus-type VAWTs in achieving greater power output was successfully demonstrated. The results of the study show that the method has great application potential for VAWTs, in general. The study also reveals that there is still a lot of room for improvement in flow analysis capabilities for low Re flows in reliably predicting post-stall aerodynamic characteristics. In the absence of such analysis capabilities, the study suggests that the results should be viewed qualitatively and not quantitatively.

\section{Acknowledgements}

The authors would like to acknowledge the support of King Fahd University of Petroleum and Minerals, Dhahran, Saudi Arabia, in accomplishing this study. The authors would also like to thank Mark Drela, MIT, and Michael Selig, UIUC, for providing the XFOIL and PROFOIL codes, respectively, for use in this study.

\section{$\underline{\text { References }}$}

(1) South, P., and Rangi, R. S., "Preliminary Tests of a High Speed Vertical Axis Wind Mill Model," National Research Council of Canada, Report No. LTR-LA74, 1971. 
(2) Paraschivoiu, I., Wind Turbine Design - With Emphasis on Darrieus Concept, Polytechnique International Press, Montreal, 2002, ISBN 2-553-00931-3.

(3) C. Masson, C., Leclerc, C., and Paraschivoiu, I., "Appropriate Dynamic-Stall Models for Performance Predictions of VAWTs with NLF Blades," International Journal of Rotating Machinery, Vol. 4, No. 2, 1998, pp. 129-139.

(4) Cissé , H., Trifu, O., and Paraschivoiu, I., "Performance Assessment of Darrieus Wind Turbine with Symmetric and Cambered Airfoils," 2007 Aero CASI Annual General Meeting and Conference, Toronto, Canada, April 24-28, 2007.

(5) Klimas, P. C., "Airfoils Treatments for Vertical Axis Wind Turbines," Windpower '85, San Francisco, August 27-30, 1985.

(6) Klimas, P. C., "Tailored Airfoils for Vertical Axis Wind Turbines," Sandia National Laboratories Report SAND84-1062, 1984.

(7) Klimas, P. C., and Berg, D. E., "Aerodynamic Design of a Mid-Sized Vertical Axis Wind Turbine Using Natural Laminar Flow Blade Elements," Sixth Biennial Wind Energy Conference and Workshop, Minneapolis, MN, June 1-3, 1983. Also Sandia National Laboratories Report SAND83-1200C.

(8) Migliore, P.G., "Comparison of NACA 6-Series and 4-Digit Airfoils for Darrieus Wind Turbines," Journal of Energy, Vol. 7, No. 4, July-August 1983, pp. 291292.

(9) Sheldahl, E., and Klimas, P. C., "Aerodynamic Characteristic of Seven Symmetrical Airfoil Sections Through 180-Degree Angle of Attack for Use in Aerodynamic Analysis of VAWT," Sandia National Laboratories Report SAND80-2114, 1980.

(10) Abbott, I. H., and von Doenhoff, A. E., Theory of Wing Sections, Dover Publications Inc., New York, 1959.

(11) Eppler, R., Airfoil Design and Data, Springer-Verlag, New York, 1990.

(12) Claessens, M. C., The Design and Testing of Airfoils for Application in Small Vertical Axis Wind Turbines, M.S. Thesis, Faculty of Aerospace Engineering, Delft University of Technology, The Netherlands, November 9, 2006.

(13) Selig, M. S., Donovan, J. F., and Fraser, D. B., Airfoils at Low Speeds, SoarTech No. 8, SoarTech Aero Publications, Virginia Beach, VA, 1989.

(14) Selig, M. S., Lyon, C. A., Giguere, P., Ninham, C.N., and Guglielmo, J. J., Summary of Low-Speed Airfoil Data - Vol. 1, SoarTech Aero Publications, Virginia Beach, VA, June 1995.

(15) Selig, M. S., Guglielmo, J. J., Broeren, A. P., and Giguere, P., Summary of LowSpeed Airfoil Data - Vol. 2, SoarTech Aero Publications, Virginia Beach, VA, May 1996.

(16) Lyon, C. A., Broeren, A. P., Giguere, P., Gopalarathnam, A., and Selig, M. S., Summary of Low-Speed Airfoil Data - Vol. 3, SoarTech Aero Publications, Virginia Beach, VA, 1997.

(17) Selig, M. S., and McGranahan, B. D., "Wind Tunnel Aerodynamic Tests of Six Airfoils for Use on Small Wind Turbines," National Renewable Energy Laboratory Report No. NREL/SR-500-34515 (Revised), Golden, CO, Oct. 2004.

(18) Mueller, T. J., (editor), Lecture Notes in Engineering: Low Reynolds Number Aerodynamics, Proceedings of the Conference on Low Reynolds Number Aerodynamics, Notre Dame, IN, 5-7 June 1989, Vol. 54, Springer-Verlag, New York, June 1989.

(19) Somers, D. M., "Design and Experimental Results for a Natural-Laminar-Flow Airfoil for General Aviation Applications," NASA TP 1861, June 1981. 
(20) Selig, M. S., Maughmer, M. D., and Somers, D. M., "A Natural-Laminar-Flow Airfoil for General-Aviation Applications," Journal of Aircraft, Vol. 32, No. 4, 1995, pp. 710-715.

(21) Gopalarathnam, A., and Selig, M. S., "Low-Speed Natural-Laminar-Flow Airfoils: Case Study in Inverse Airfoil Design," Journal of Aircraft, Vol. 38, No. 1, Jan.Feb. 2001, pp. 57-63.

(22) Greer, D., Hamory, P., Krake, K., and Drela, M., "Design and Predictions for a High-Altitude (Low-Reynolds-Number) Aerodynamic Flight Experiment," NASA/TM-1999-206579, July 1999.

(23) Drela, M., "Low-Reynolds-Number Airfoil Design for the M.I.T. Daedalus Prototype: A Case Study," AIAA Journal of Aircraft, Vol. 25, No. 8, August 1988, pp. 724-732.

(24) Drela, M., "XFOIL: An Analysis and Design System for Low Reynolds Number Airfoils," Low Reynolds Number Aerodynamics, edited by T. J. Mueller, Vol. 54 of Lecture Notes in Engineering, Springer-Verlag, New York, 1989, pp. 1-12.

(25) Drela, M., and Giles, M. B., "ISES: A Two-Dimensional Viscous Aerodynamic Design and Analysis Code," AIAA Paper 87-0424, Jan. 1987.

(26) Giles, M. B., and Drela, M., "Viscous-Inviscid Analysis of Transonic and Low Reynolds Number Airfoils," AIAA Journal, Vol. 25, No. 10, October 1987, pp. 1347-1355.

(27) Drela, M., "MSES: Multi-Element Airfoil Design and Analysis Software," M.I.T. Aerospace Computational Design Lab, 1994.

(28) Selig, M. S., and Maughmer, M. D., "A Multi-Point Inverse Airfoil Design Method Based on Conformal Mapping," AIAA Journal, Vol. 30, No. 5, 1992, pp. 11621170.

(29) Selig, M. S., and Maughmer, M. D., "Generalized Multipoint Inverse Airfoil Design," AIAA Journal, Vol. 30, No. 11, 1992, pp. 2618-2625.

(30) Kadlec, E. G., "Characteristics of Future Vertical Axis Wind Turbines," Sandia National Laboratories Report SAND79-1068, Nov. 1982.

(31) Selig, M. S., and Maughmer, M. D., "Development and Application of a Multipoint Inverse Design Method for Horizontal Axis Wind Turbines," Wind Engineering, Vol. 19, No. 2, 1995, pp. 91-105.

(32) Blackwell, B. F., Sheldahl, R. E., and Feltz, L. V., "Wind Tunnel Performance Data for the Darrieus Wind Turbine With NACA 0012 Blades," Sandia National Laboratories Report SAND76-0130, Mar. 1976.

(33) Saeed, F., and Selig, M. S., "Multi-Point Inverse Airfoil Design Method for SlotSuction Airfoils," AIAA Journal of Aircraft, Vol. 33, No. 4, July-Aug. 1996, pp. 708-715. Also AIAA Paper 95-1857.

(34) Saeed, F., Selig, M. S., and Bragg, M. B., "Design of Subscale Airfoils with FullScale Leading Edges for Ice Accretion Testing," AIAA Journal of Aircraft, Vol. 34, No. 1, Jan.-Feb. 1997.

(35) Saeed, F., Selig, M. S., and Bragg, M. B., "Hybrid Airfoil Design Method to Simulate Full-Scale Ice Accretion Throughout a Given $\alpha$ Range," AIAA Journal of Aircraft, Vol. 35, No. 2, Mar.-Apr. 1998.

(36) Berg, D. E., "An Improved Double-Multiple Streamtube Model for the Darrieus Type VAWT," Proceedings of the Sixth Biennial Wind Energy Conference and Workshop, Minneapolis, MN, June 1983, pp. 231-238. 


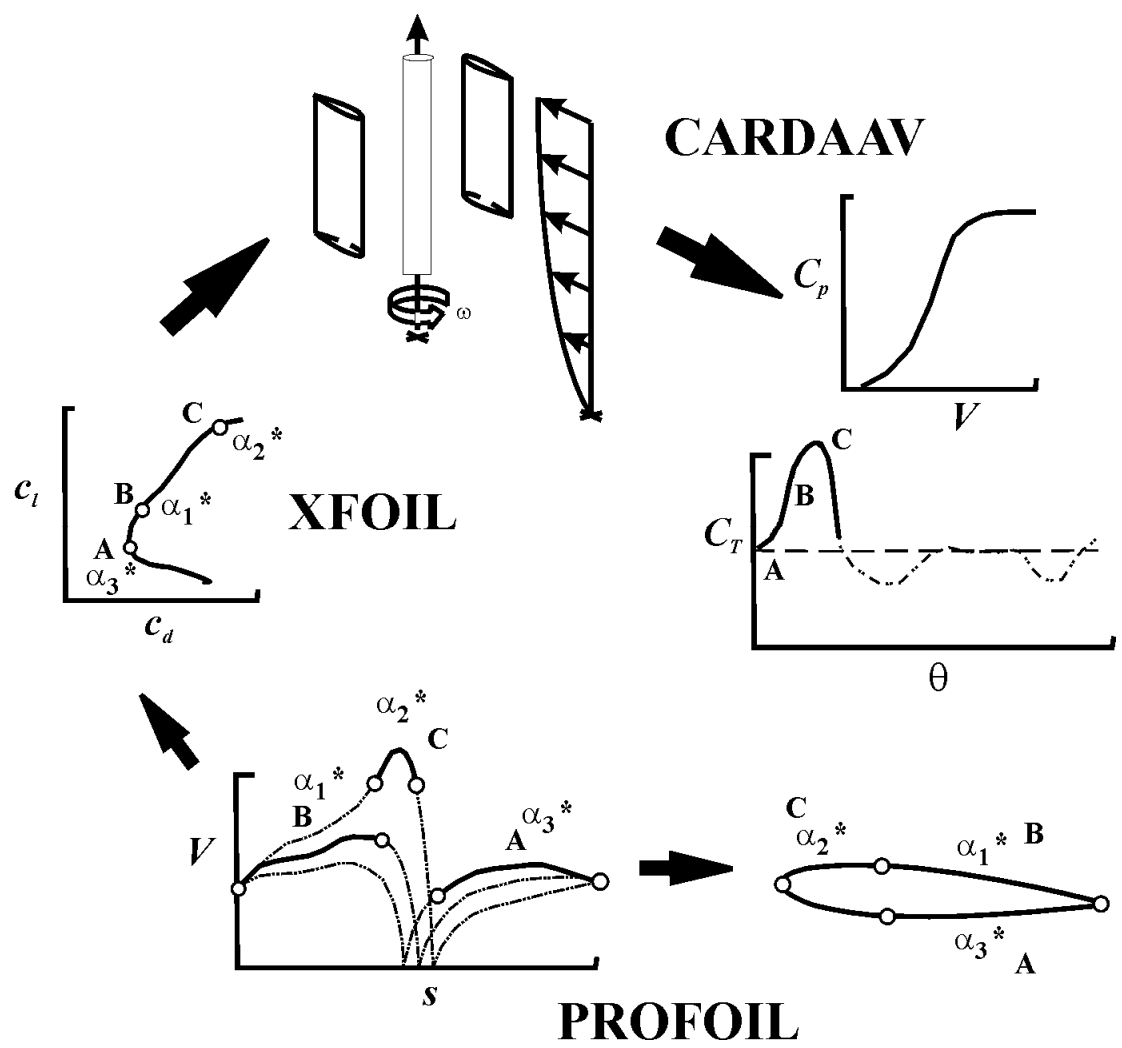

Figure 1: The inverse airfoil design strategy as employed for improved performance of a VAWT

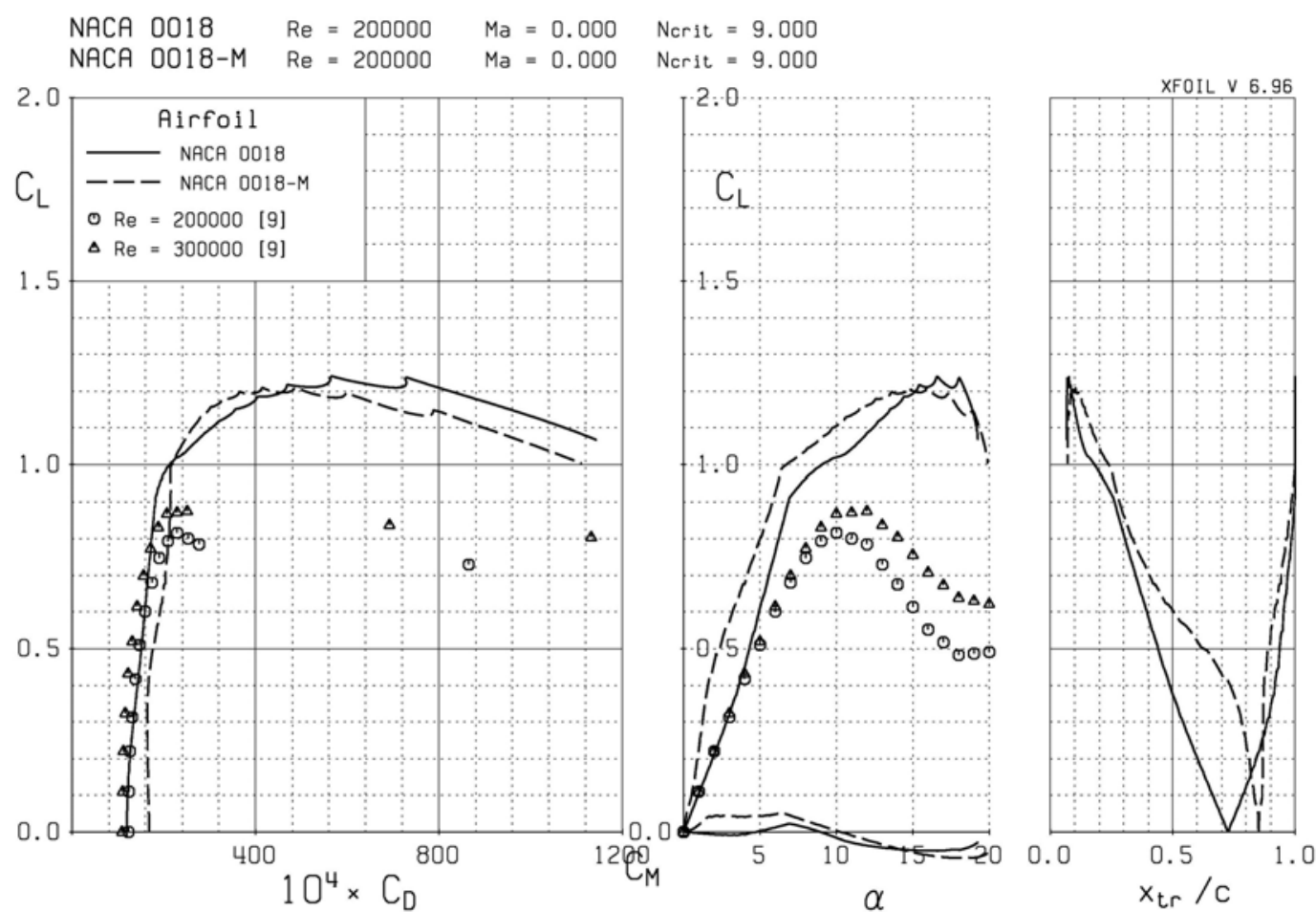

Figure 2: Comparison of aerodynamic and boundary layer characteristics of the original NACA 0018 airfoil and the final design NACA 0018-M airfoil with experiments. ${ }^{9}$ 


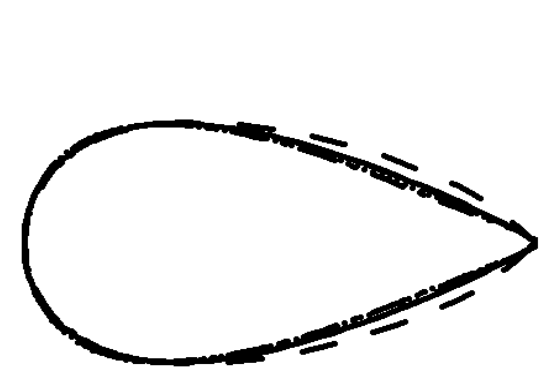

(a)

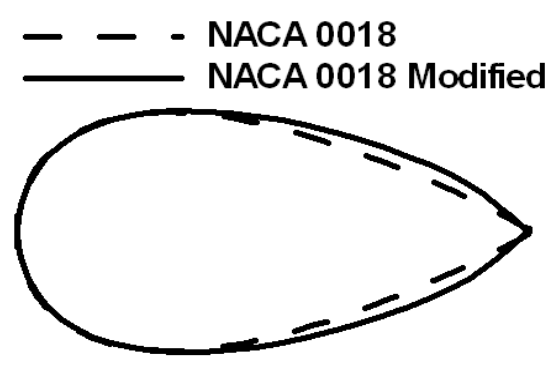

(b)

Figure 3: (a) Evolution of the design. (b) Final design compared to the original NACA 0018 airfoil. (Note: the y-axis has been greatly exaggerated to highlight difference in the airfoil shapes)

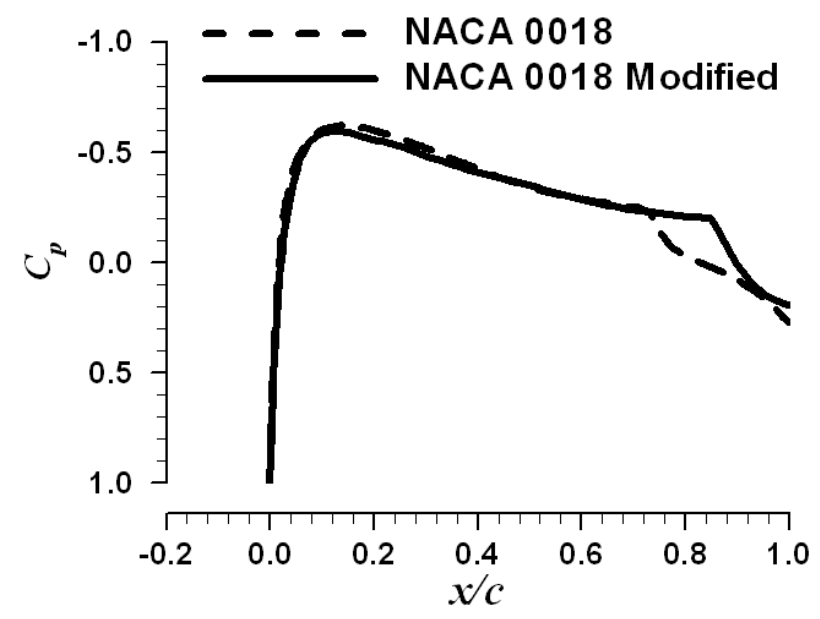

Figure 4: Comparison of surface pressure coefficient distribution at $\operatorname{Re}=200000$ and $\alpha=0$ deg.

Table 1: Comparison of power output for three different airfoils

\begin{tabular}{lccc}
\hline \multicolumn{1}{c}{$\boldsymbol{C}_{\boldsymbol{l}}-\boldsymbol{C}_{\boldsymbol{d}}$ data source } & Power (kW) & $\boldsymbol{C}_{\boldsymbol{P}}$ & $\boldsymbol{C}_{\boldsymbol{Q}}$ \\
\hline \hline NACA 0018 (Experiments) & 0.748 & 0.136 & 0.085 \\
NACA 0018 (XFOIL+ Experiments) & 1.610 & 0.294 & 0.184 \\
NACA 0018-M (XFOIL+ Experiments) & 1.850 & 0.338 & 0.211 \\
\hline
\end{tabular}

